\title{
EDITORIAL
}

\section{ACCIDENTS AND ACCIDENTAL INJURY}

IN this issue we present a review by Mr. A. H. Gould, Principal Scientific Officer, Ministry of Defence (Army Department) A.M.D. Stats, of the Report on the Health of the Army for 1965.

Inter alia, he makes the point that the injury rate (as indicated by numbers of admissions of British Army personnel to medical units) has for the first time for many years shown a slight decrease. This is of the order of 5 per cent overall, although not constant between all theatres. It is, of course, impossible to predict, but it is certainly to be hoped that this points to a reversal of the rising trend of injury admission rates which has been a feature of annual reports since the immediate post-way years. It will be appreciated that such reports relate only to admissions to medical units, and it would be necessary to make a detailed study of minor morbidity statistics in addition, in order to arrive at a true assessment of the picture.

Nevertheless, it may be opportune to consider whether this important aspect of conservation of military manpower is receiving due emphasis in the principles and practice of the Army Medical Services. It is evident that in this context a great deal of responsibility falls on military commanders and others who are not of these Services, but we have in our charter a clearly defined responsibility to advise on any matter which may, in our opinion, conduce to the preservation of the health of the troops (Regulations, 1954a). This clearly makes us active members of any team, at any level, the activities of which are directed to the prevention of accidents or of accidental injury. Our role may be advisory or it may be executive.

In the field of medical classification, for example, we have direct responsibilities. On our correct assessment of a man's visual acuity and degree of colour perception will depend his acceptance and at least in these respects, his safety as a driver. Following a routine PULHEEMS re-assessment or as a result of examination by a medical board, a soldier may or may not be judged fit to continue with or to resume his employment. This is of special importance if inability to properly exercise his duties is liable to place the safety of himself or of others in jeopardy. Our efficient discharge of such responsibilities demands that we have an adequate knowledge of the soldier's way of life and of his environment. This implies the need for a close liaison between the Army Medical Services and their actual or potential patients and their commanders. While it is probably true to say that this can be most fully achieved at regimental medical officer or general practitioner level it is also desirable for such an understanding to be acquired by the staffs of hospitals and other medical units.

Rosenbaum (1967) surveyed sport played in the Army and related this to injuries incurred. It will be noted from Gould's review that injuries sustained during athletics and sport accounted for one fifth of injury admissions. It is well recognised that a high degree of physical fitness lessens the risk, whether in sporting or other military activities involving physical exertion, and the necessity for progressive training leading up to strenuous activity is obvious. This in its turn demands that unit medical officers in particular must work closely with regimental and Army Physical Training Corps instructors. These points have been will brought out by Kirkman (1966) in his description of circuit training as adapted to recruits. 
In industry, it has been shown that the accident rate tends to rise when workers are tired or under some degree of emotional stress, perhaps due to personal or family problems. It might be said that these are matters strictly related to unit administration and man-management, but our duty to observe, individually or collectively, and to advise appropriately cann ot be evaded.

Nor should it be forgotten that in the event of an injury being sustained, the immediate or residual effects may well be determined by the standard of first aid treatment available, which is largely influenced by the interest taken by medical officers in the teaching of this subject.

Traditionally, and correctly, the provision of protective equipment which is taken (or not taken) into use largely at the discretion (or indiscretion) of the individual, comes well down in the order of priority in accident or injury prevention. None the less, such equipment has a place. The use of ear defenders-lineal descendents of the cotton wool and soft paraffin plugs of many years' standing-is of particular.importance in today's Army, with exposure of its members to noise levels higher than ever before (Livesey, 1965). There are both physical and psychological difficulties attendant on the diligence with which these are used. The former may be dealt with relatively easily by proper fitting, but the latter requires repeated, reasoned education at all levels and in this we must play our part in full.

It is apparent that when any problem is to be tackled, the more the information available, and the greater the extent to which this information is analysed, the clearer will be possible lines of solution. Gould has referred to the Table in the 1965 Report which gives a breakdown of injury admission by nature and external cause, and the work of Rosenbaum (1967) has been cited above. These are most valuable studies, and must surely be regarded as stimuli to further action. Is there not a requirement for each and every accident and accidental injury, even if not resulting in death or admission to hospital, to be critically investigated with a view to answering two questions:-Why did this happen and what can be done to prevent it happening again?

Finally, is there a case for paragraph 21 (a) of Regulations (1954b) to be amended to read 'For the promotion and maintenance of health and for the prevention of disease and injury'?

\section{REFERENCES}

Kirkman, M. F. (1966). J. roy Army med Cps. 112, 136.

LIVESEY, B. (1965). J. roy. Army med. Cps, 111, 188.

Regulations for the Medical Services of the Army (1954a). p.1. War Office, London.

Ibid. (1954b) p.1.

Rosenbaum, S. (1967). J. roy Army med Cps. 113, 65.

\section{" I HEREBY SUBMIT FOR PUBLICATION . . . . . . "}

The Journal of the Royal Army Medical Corps was first published in July, 1903, and on the opening pages of the first number of the first volume appears 'L'ENVOI ' by Sir William Taylor, K.C.B., M.D., K.H.P., then the Director General of the Army Medical Service, which appointment he held from 3rd December, 1901 until his retirement on 2nd December, 1904.

Sir William noted that the issue of the Journal was the realisation of a hope of many years; the establishment of a Journal had indeed been agreed at Netley in 1864, but for a variety of reasons publication had been shelved repeatedly. 
He went on to say - That men who have had unusual experiences and have had much of interest to tell their brother officers and the scientific world generally have been kept from doing so, has been in a great measure due to the fact that all communications, however great their interest, were consigned to the limbo of the Army Medical Department Report. Some lethal influence seems to have lurked in the pages of that official publication, for everything that entered them was suffocated at birth and annihilated. No future existence was possible for anything overtaken by that misfortune.

It is believed, therefore, that officers will hail with joyous appreciation the appearance of this Journal, that they will eagerly take advantage of the opportunities which it will afford them of interchange of ideas on the many subjects if importance to individual officers as well as to the Service to which they belong'.

Sir William's belief was amply justified and the subject matter of the Journal over the many years which have followed ' L'ENVOI' is due testimony to the eagerness of officers which he anticipated. Is it, however, possible that this eagerness is undergoing a temporary eclipse? It surely cannot be that aspiring authors have access to less material on which to base contributions. Is it perhaps due to diffidence-the feeling that a case report, an investigation or a military experience will be of insufficient interest to merit publication-that the editor is currently scanning his register of 'Papers Received' with some anxiety? The plea, then, is for contributions and for the continuance in the pages of the Journal of the interchange of ideas which was envisaged over sixty years ago.

In this issue, the general advice which regularly appears on the inner side of the front cover is supplemented by rather more detailed notes for contributors, acknowledgement of which is made to Lieutenant-Colonel R. J. C. Hart, who until his recent retirement was the Journal's Honorary Assistant Editor. It is hoped that these notes and the references thereto will form a useful guide to intending authors.

\section{NOTICE TO SUBSCRIBERS}

IN January, 1966 subscriptions to the Journal and Army Medical Services Magazine were increased to offset higher costs.

The new subscription rates were notified to subscribers by the Chairman of the Committee of the Journal of the R.A.M.C., Lieutenant-General Sir Robert Drew, and also by publication in Volume III, Number 4, of 1965.

These notifications do not appear to have reached all our subscribers as the management note that some 10 per cent have not yet amended their banker's orders to cover the new rates of subscription.

The old and new rates are printed below in order that subscribers may check that they are paying at the correct rates.

Journal only Old rate New rate

\section{Journal and Magazine}

f1. $0.0-$ £1. 8. 0

All subscribers who have not yet completed a new banker's order are requested to complete the order form which will be found in this issue and forward this to the Manager, Journal of the Royal Army Medical Corps, R.A.M. College, Millbank, London, S.W.1. together with a cheque to cover the balance of subscription from 1st January, 1966. 